\title{
INTRODUCTION \\ Integrating young people of different religious and ethnic \\ backgrounds in our schools
}

\author{
Ratna Ghosh (McGill University) \\ Denise Lussier (McGill University) \\ Gretta Chambers (McGill University)
}

\section{CONTEXT}

Modern societies, all around the world, are discovering that modernization, what we call progress and development, has not brought with it the harmonization and cultural homogenization that has long been predicted. The thesis used to be that modern social conditions like social differentiation, individualism, the break-up of earlier communities which superseded the social contexts of the past when religion flourished, would weaken the hold of religion and therefore free up adherents of various dogma, doctrines and supernatural allegiances to join the ranks of the information society. The electronic age, it was believed by some, with its emphasis on the industrial, the scientific-technological thrust of urban agglomerations would not provide propitious conditions for religious dominance and would lead to secular democratic societies. But, in order to build a common understanding of democracy that includes everyone, an understanding which fosters common political identity and mutual trust is essential. This goes beyond the tolerance that, so often, is simply a thin layer of behaviour pattern camouflaging deep seated reservations about people who aren't like 'us'.

What is now becoming increasingly clear is that globalization and modernization are not universal in their impact on different cultures. Every society must come to terms or make peace with these inescapable worldwide trends, but the effects of those trends are different and can be very diverse in different societies. One of the salient factors in this diversity lies in the too narrow frame in which we view religion today. By not taking into account the wide variety of beliefs, practices and institutions which the concept of "religion" encompasses; by not factoring in varying time-lines under which different parts of the world attempt to adjust to the globalization of knowledge, information and technology to which we are all subjected, we have no way of gauging the exact effects of modernization as it is lived in different cultural settings.

We must remember that we live in a world in which ideas, institutions, art styles, and formulae for production and living circulate among societies and civilizations which are very, very different in their historical roots and traditional 
forms. Those ideas and forms do not just change place as solid blocks. With each transfer they are changed, acquiring a different spin, and new meaning, and thus much confusion and misrepresentation can occur.

So far, all these different factors and new challenges have created certain threats among people from many societies. It seems that globalization, international migration and world-wide communication have increased religious and ethnic diversity. State policies range from homogenization/assimilation, adaptation, accommodation, to various forms of incorporation, integration, inclusion and recognition. Moreover, some events in North America (post 9/11 and the Muslim mosque on Ground Zero paranoia) and Europe (riots in the suburbs of Paris, assaults on public transportation in Great Britain, and government ban on certain new practices such as the full-face veil in public by defiant young Muslim women in some European countries) indicate that youth of religious and ethnic minorities have not been successfully integrated in many societies so that they do not have a feeling of belonging. Public education and educational policies have failed to achieve explicit objectives, namely, to develop in all young people a high degree of acceptance of self and each other so as to feel included in society and become productive citizens who have access to equal opportunity and outcome. Moreover, some religious groups (Muslims, Sikhs) are stereotyped as fundamentalist, and ethnic groups are marginalised. Their youth become targets for forms of oppression: exclusion, exploitation, powerlessness, cultural imperialism and violence. What are needed are strategies of recognition and inclusion (Young, 1990; 2000) in school and society. Yet, little is known about daily practices of recognizing and including religious beliefs and group ethnicity within public schools while maintaining democratic secularism and respecting human rights. Similarly, little is understood about how different philosophies, immigration policies and patterns, socio-economic, political, cultural, racial and historical factors impact on educational systems, religious beliefs of young people and the construct of identity. The challenge is to have healthy integration without assimilation that erases the religious and cultural identity of minorities; this has to be achieved without compromising the secular character of democracies. The research focus to date has been to examine cultural boundaries and representations rather than religious boundaries and religious representations which are central to the integration of minority groups. Public schools confront the dilemma of accommodating religious beliefs almost on a daily basis and attempt to respect human rights while maintaining democratic secularism.

Since the horrific happenings of $9 / 11$ in the United States and the globalization of terrorism, the word multiculturalism has developed greater 
negative connotations. All people of colour are suspect and tend to be thought of as a homogenous group. Largely due to ignorance, all non-whites are viewed by some as Muslims and potential terrorists, and all Muslims are lumped together despite the fact that a Muslim from Indonesia has very little in common with a Muslim from the Arab world. Furthermore, people from certain geographical areas are thought to be Muslims such as an Egyptian who is a Coptic Christian and is not to be confused with being a Muslim. Moreover, all these "coloured" populations are perceived, at least by the proverbial "common" white person, as potentially subversive. This is because the difference in "shades" of colour is not the point: "coloured" here is "different" - even when some "colours" are quite "white". In such perspective, concepts of diversity, and hybridity of identities have to be addressed by all societies, and mostly specifically in terms of citizenship education.

\section{DIVERSITY and HYBRIDITY}

The need is to have nuanced and contexualized interpretations of multiculturalism to avoid a binary system of representation, which solidifies and normalizes the gap between the "Us" and "Them". The complexities surrounding the concept of identity decry fixed, essentialist, and static notions of identity. In Edward Said's words, "No one today is purely one thing. Labels like Indian, or woman, or Muslim, or American are no more than starting points...Imperialism consolidated the mixture of culture and identities on a global scale. But its worst and most paradoxical gift was to allow people to believe that they were only, mainly, exclusively, white, or black, or Western, or Oriental" (Said, 1993, p. 408).

Categorizing people has no validity because, as pointed out above: no one today is purely one thing. Hybridity is a cultural effect of globalization and "traces of other cultures exist in every culture" (Kraidy, 2005, p. 148). This mixture of cultures is particularly true in immigrant societies. In Canada, intermarriage is growing, as are inter-religious and interracial unions, and as much as $41 \%$ claimed mixed heritage in the 2006 mini census (Statistics Canada, 2007). Problems of integration are likely to shift from racial/ethnic/cultural/religious markers to socio-economic and political power ones. So, in Canada we need to rethink the traditional 'us-them' dualism and develop a more critical perspective of multi/inter-cultural politics which not only accepts difference as essential to the development of societies but also negotiates both differences and similarities.

The very concept of hybridity is central to our thinking of a multicultural/intercultural Canadian society because it is "celebrated and 
privileged as a kind of superior cultural intelligence owing to the advantage of inbetweenness, the straddling of two cultures and the consequent ability to negotiate the difference." (Hoogvelt, 1997, p. 158) Bhabha developed his concept of hybridity from literary and cultural theory to describe the construction of culture and identity within conditions of colonial antagonism and inequity (Bhabha 1994; Bhabha 1996). For Bhabha, the new hybrid identity or subjectposition is a mutual sense of "both/and" which disputes the authenticity or purity of any essentialist cultural identity (Ashcroft et al., 1995). Bhabha points out the dangers of fixity and fetishism of identities arguing that "all forms of culture are continually in a process of hybridity."

Taking from post-colonial theory, Bhabha's concept of the in-between cultural spaces is what he refers to as the third space. It is from here that new cultural positions emerge indicating new possibilities which diffuse boundaries of cultures and identities. This is essential for diverse societies because it implies a politics of inclusion rather than exclusion giving rise to a transcultural (Taylor, 1991) identity which is dynamic because it straddles and constantly negotiates within two or more cultures. In no way does this obliterate one's roots (Meredith, 1998) but it recognizes the post-migration reality of all Canadian.

\section{SCHOOLS and RELIGIOUS BOUNDARIES}

One of the major issues in the new millennium is the re-emergence of religious boundaries and representations in the construction of youth identity. Given the relevance of religion in the articulation of cultural and ethnic identities, how does the relationship between religion and race relations affect public policy? Democratic multicultural societies must consider the significance of religious diversity in public educational institutions as they produce citizens. Education is central to the development of political identifications and is viewed as socialisation of youth into cultural ways of knowing, believing, doing and valuing. Education can be a means to social cohesiveness. Therefore, focus on the role of education in "managing" religious diversity and ethnicity is important. It is crucial at this point in history to rethink the place of beliefs, images and practices in public education in pluralist democratic societies.

An overarching question is: How can public schools successfully manage the integration of children of different religious backgrounds so that they can participate fully in the life of the school? Related questions at the micro level are: How do schools balance their religious and ethnic heritage with contemporary secularity within the context of the integration of young people of diverse religious and ethnic backgrounds? How do norms of reference and curriculum support schools in making all students feel good about their identities, 
thus sustaining stability in religious and citizenship education? More specifically: What bases are available to public schools, in evolving multicultural and multifaith societies, upon which to base their social justice strategies? Do national ideologies and policies such as secularism make a difference in school policies favouring equality and access, and student's perceptions of equality and recognition?

\section{CONCEPTUAL FRAMEWORKS}

A greater understanding of the relationship of religion and education is essential in order to generate a common conceptual framework for understanding issues of conflicts beyond the politics of difference. One way to do this would be a collaborative international research project to be carried out with schools of several pluralist democratic societies in North America and Europe. With a largescale research project, the attempt would be to document best practices which will prompt discussion of various possibilities and policies to foster peace in the world through education. Research and scholarship on issues of social integration tend to overlook the participation of youth. The development of a two-stage collaborative project proposal could first focus on each country having empirical research on questions which seek the various points of view of youth. For example: How do youth of religious and racial minorities think of difference with respect to their identity formation and integration in pluralist democratic societies? How do students react to the strategies that schools employ to create and sustain socially just and inclusive environments in evolving multicultural, multiracial and multi-faith societies? In a second stage, and taking into account the data from the first phase, research should aim for the development of a systematic approach applicable to the design of new curricula, the integration of new pedagogical approaches, and the creation of new types of textbooks in order to foster social cohesiveness.

It is also necessary to emphasize the enormous advantages of diversity in a modern society such as Canada: it promotes creative understanding of problems from multiple perspectives and pools talents from a very large array of fertile minds. There is much empirical evidence to support this in many fields such as education, science, technology and medicine. Immigrants create wealth and well being in society-social, material and intellectual. It is also interesting to consider how the province of Quebec, which is referred to as a Catholic and French speaking population with specific distinctions, is trying to adapt school policies and curriculum to new societal challenges due to the emergence of new intercultural and religious diversities. 


\section{QUEBEC and RELIGION}

Although there has never been a complete separation of Church and State in Quebec (as in France) the affirmation of secularism has come most recently in relation to Muslim symbols of religious traditions. Secularism is essentially insistence on the separation of religion and government. Although secularism is a significant movement in modernization, it is interpreted in different ways. It is useful to look at differences in state ideologies in terms of secularism. These can range from "passive secularism," in which the state allows public visibility of religion as, for example in the United States. On the other hand, "assertive secularism," in which the state plays a proactive role in excluding religion from the public sphere, especially from schools as in France. In contrast to secularism in the West where the concept and philosophy was a result of conflict between the Church and State, secularism in India is a state philosophy which upholds religious and cultural pluralism.

In Canada, where education is a provincial responsibility, the Anglophone provinces would fall into the passive secular category. However, the Francophone province of Quebec is assertively secular, especially in its school system. Let us look at the example of Quebec. In the province of Quebec there is a debate over the issue of religion in the schools. People are deeply divided, confused or angry about differing opinions about the proper place of religion in public places. Quebec is largely a homogenous society (except in Montreal, its largest city), and there was a consensus when it was under the domination of the Catholic Church. The start of the secular movement in Quebec in the late 1940s was tied to the rise of the unions trying to break from the control of the Catholic Church. This was solidified in the emergence of nationalism and the sovereignty movement during the Quiet Revolution in the 1960s. Ironically, the need for immigration (due to the sudden low birthrate as a result of the decreasing influence of the Catholic Church) brought people of diverse religious backgrounds and unfamiliar customs in contact with a previously homogenous population. This eventually led the premier of the province to set up The Bouchard-Taylor Committee in 2007; a high profile committee to look into the extent to which the host society-the Francophone population-should accommodate various religious and other practices.

The Bouchard-Taylor report on the 'reasonable accommodations' (2008) has brought many discussions and positive or negative comments in terms of explaining some aspects of the reality as perceived by different ethnic and religious groups. However, there is a need to go beyond the context of such a report to reach a higher level of dialogue aiming at finding solutions to the new 
challenges of modern societies not to be considered anymore as homogeneous but as heterogeneous in terms of religion and ethnicity.

The Ministry of Education in Quebec introduced a mandatory Ethics and Religious Culture course throughout the school curriculum to replace any religion courses in the public system. While this course is still being challenged in the courts, it aims to cultivate "literacy" on the significance of religion on the daily lives of people. An impressive undertaking, this course is intended to foster in students ethics and moral competency, and a capacity to understand religion in its many dimensions which the Ministry considers essential in a pluralistic secular democratic society (Morris, 2011.)

The point of a school approach to religion in which everyone learns about all religions is not a denial of one's faith. The goal is rather, to build a common democratic culture in which each citizen can respect others' faiths. The goal is to build a democracy that is both religiously accepting and religiously knowledgeable (Fraser, 1999). There are several ways to consider education's role in developing openness to Otherness and diverse cultures: accepting heterogeneity; developing positive concept of self and understanding of differences (without misusing them), the construct of identity in relation to violence in schools and ethnic heritages, cultural roots and religious beliefs. Citizenship education is most important. The emergence of common frameworks of reference for the development of intercultural and interreligious competence has led to the development of and new approaches to generate new educational curricula and pedagogical practices.

\section{SPECIAL ISSUE}

This issue of the Journal is designed to broaden our horizons so that we better understand the social and educational impact of diversity on the globalization, modernization and mobility as a non universal phenomenon. It has been divided into three sections.

Section One covers concepts and issues. The opening paper by Ratna Ghosh and Jaswant Guzder considers re-bordering as an aspect of globalization. Nowadays, borders have become impervious to national/political and even cultural boundaries. People's identities are no longer being stable and fixed. They are constantly in a state of flux. Since $9 / 11$, there has been a significant change in how cultural/religious minorities, especially how people from certain parts of the world are identifiable, more if they are Muslims. Their paper addresses the issue of South Asian (SA) refugees in Western countries as they are potentially in danger of being stereotyped as "terrorists". From the point of view of these 
immigrant students, cultural, religious and psychological identities are being constantly challenged. This is particularly true because they are often faced with radically different value systems. The literature on SA students indicates that borders of social class and space make a big difference to their education and achievement. Success depends disproportionately on family and ethnic community resources while failure is due to the lack of ethnic community resources. Unfortunately, underachievement has focused on cultural and linguistic deficits rather than how youth negotiate their identities. The paper consists of data from two empirical investigations as part of a larger study on Schools, Culture and Mental Health: a Society in transformation. It presents the theoretical framework and argues that knowledge is a consequence of identity and social location. It also discusses the experiences of two groups of SA students in a low socio-economic neighbourhood in Montreal on the construction of bordering and re-bordering. It brings the concept of transnational identity.

The second paper by Denise Lussier explores the complex relationship between language, thought and (inter)culture. It argues that language competence needs to address not only the linguistic, sociolinguistic and pragmatic/discourse elements of langue but should integrate (inter)cultural interactions and transactions between individuals in the learning process. It reviews existing theories and models of intercultural communicative competence. It also proposes a conceptual framework which involves cognitive, affective and psychological factors; the three essential domains being intercultural 'knowledge', intercultural 'skills' and intercultural 'being'. It questions how, in a context where geopolitical interests predominate, we view cultural and intercultural issues, how we can promote values and attitudes that recognize experiences of diversity and openness to other cultures, and how institutions such as schools and universities can promote social cohesion through education. It brings the concept of transcultural competence. It also questions the relationship that also exists between religion, thought and (inter)culture, and a possible transfer to a 'religious' conceptual framework referring to cognitive, affective and psychological factors; the three essential domains being religious 'knowledge', religious 'skills' and religious 'being'.

Section Two gathers together some valuable insights on identity. Valérie Amireault' s opening paper analyses the construct of identity of adult immigrants learning the language of the target society that they have adopted. It considers integration into the host society as closely linked to language learning and to all the cultural aspects that lie behind the mastery of the official target language. It is a process likely to cause a stir within the cultural identity of 
immigrants. They must find a balance that will allow them to create a new identity in order to achieve their integration. For an individual or a group, language is a symbolic marker and a manifestation of identity since it is one of the most important factors used to categorize others and to define ourselves. As language is a manifestation of cultural identity, the language a person speaks bears the imprint of the cultural community to which he/she belongs. As such, language is not a neutral medium of communication but it is closely related to the social context in which it is used. Findings suggest that participants experience a "me-them" cultural duality referring to a hybrid identification.

Amina Triki-Yamani reports on French Muslim women students and their relationship to knowledge. These women live in France and their custom is to wear the hijâb and to attend the mosque regularly. The research tends to analyse students' identity strategies and to understand how adopting the 'strategy of a return to stigmatization' seems to increase their conflicting relationship to secular learning. It also explores the psychic functions of the hijâb that permit the women to readjust their self-identity as well as their internal conflicts.

Section Three offers reflections on diversity in accommodating differences in diverse contexts such as England, and a case study of South Asian school-aged refugees from conflict regions in Bangladesh, Sri Lanka, India and Pakistan in Montreal.

The first paper by Julia Ipgrave refers to two educational and religious incidents that have featured in the England press over the last few years: the wearing of the hijab by Muslim pupils and the teaching about Creation theories as part of religious education. Both of these cases are exploring the limits of the inclusion of pupil's religion in school. They show how, after three decades of discussion about the degree to which religion in an increasingly religiously plural society should be accommodated with school routines, practice or curriculum content, the subject still remains controversial in England and the situation fluid. Two different approaches of inclusion are to be considered: the accommodation of outward manifestations of the pupil's religious identity and the welcoming expression of their beliefs and worldviews as part of the learning process. Two forms of inclusion are defined: permissive and affirmative.

The paper by Jaswant Guzder presents clinical vignettes of mental health interventions with South Asian school aged children in Canada within the specific context of Quebec as a window for a discourse on parent, child, school and mental health interfaces. While previous generations of migrants had been predominantly educated professionals, demographics shifted to an heterogeneous migrant population from various ethnic, socio-economic and educational 
backgrounds. It is likely that children of these populations had a higher risk of traumatic experiences prior to migration due to familial or political trauma. Canadian metropolises are experiencing increased stress related to violence, drug abuse, academic and mental health problems. In terms of vulnerabilities, these child populations would benefit from identifying with the host society as well as having the implicit influences of their countries of origin cultures. This psychological bicultural space is complex as it is negotiated in the realm of multiple influences. This paper underlines the need for alliances that bridge institutional discourses with parents and children. It suggests the integration of a cultural axis to widen our ethnocentric Euro-North American value system to expand our ethical considerations for intervention aims. Five study cases are discussed to illustrate the roles of schools, mental health and social services as important factors to provide support and counselling services to distressed students.

The concluding paper by David Birnbaum gives a brief description of the new challenges that are facing the Quebec English School Boards Association (QESBA) which represents the 350 English public schools of Quebec. It has been ten years since Quebec school boards were re-organized along linguistic rather than confessional lines. The new current context brings new realities. The paper includes a few examples of the general approach of the English school system in Montreal in the area of diversity and reasonable accommodation.

With its broad coverage of some key contemporary issues, not specific to one province or one country, combining theoretical insight and practical input, this issue of the Journal constitutes a valuable reference work and a useful resource for researchers in different countries who wish to extend their knowledge and broaden their understanding of the educational impact of ethnic and religious diversity on modern societies, and the construct of identity of new immigrants and «personnes de souche» in their search for openness to other cultures and alterity.

\section{ACKNOWLEDGMENTS}

We would like to express our thanks to all the Journal issue contributors for developing and taking the time to write up their original presentations given at McGill International Colloquium on Diversity and critical issues of the next decade in education that was held on December 4 and 5, 2008.

We are also grateful to Katherine Mikic for her help throughout the organisation and development process. 


\section{References}

Ashcroft, B., Griffiths, G., \& Tiffin, H. (Eds.). (1995). The Post-colonial Studies Reader. London: Routledge. Bhabha, H. K. (1994). The Location of Culture. London: Routledge.

Bhabha, H. K. (1996). Cultures in Between. In S. Hall \& P. Du Gay (Eds.), Questions of cultural identity (pp. 53-60). London: Sage Publications.

Bouchard, G. r., \& Taylor, C. (2008). Building the Future: A time for reconciliation, from http://www.accommodements.qc.ca/index-en.html

Fraser, J. (1999). Between Church and State: Religion and Public Education in a Multicultural America. New York: St Martins Griffin

Hoogvelt, A. (1997). Globalization and the Postcolonial World: The new political economy of development. Baltimore: The John Hopkins University Press.

Kraidy, M. (2005). Hybridity, or the Cultural Logic of Globalization. Philadelphia: Temple University Press.

Meredith, P. (1998). Hybridity in the Third Space: Rethinking Bicultural: Rethinking Bi-cultural Politics in Aotearoa/New Zealand. Paper presented at the Te Oru Rangahau Maori Research and Development Conference, Massey University.

Morris, R. (2011). Quebec's Ethics and Religious Culture Program: Controversy, Content and Orientations. Canadian Issues, Special Edition (Spring), 55-59.

Said, E. (1993). Culture and Imperialism. New York: Alfred Knopf.

Statistics Canada (2007). Census 2006 data. Ottawa.

Taylor, D. (1991). Tranculturating Transculturation. In B. Marranca \& G. Dasgupta (Eds.), Interculturalism and Performance (pp. 60-74). New York: PAJ Publications.

Young, I. (1990). Justice and the Politics of Difference. Princeton, NJ: Princeton University Press.

Young, I. (2000). Inclusion and Democracy. Oxford: Oxford University Press.

Ratna Ghosh is James McGill Professor and William C. Macdonald Professor of Education at McGill University. Her research interests focus on issues related to diversity and discrimination. She can be contacted at ratna.ghosh@mcgill.ca.

Denise Lussier, Professor Emerita McGill University, Educational Psychologist and Docimologist does research in the areas of intercultural communicative competence in education, measurement and evaluation and development of curriculum. She can be contacted at denise.lussier@mcgill.ca.

Gretta Chambers, CC, OQ, LL.L is Chancellor Emerita of McGill University. She has enjoyed a long and distinguished career as a journalist and is a recognized expert in Quebec politics and society. 